\title{
The Effect of Deoxycholic Acid on Secretion and Motility in the Rat and Guinea Pig Large Intestine
}

\author{
Nam Hee Kim, ${ }^{1}$ Jung Ho Park, ${ }^{1 *}$ Jae-soon Park, ${ }^{2}$ and Yeun-Ho Joung ${ }^{2}$ \\ ${ }^{\prime}$ Department of Internal Medicine, Kangbuk Samsung Hospital, Sungkyunkwan University College of Medicine, Seoul, Korea; and ${ }^{2}$ Department \\ of Electronics and Control Engineering, Hanbat National University, Daejeon, Korea
}

\section{Background/Aims}

Bile acid is an important luminal factor that affects gastrointestinal motility and secretion. We investigated the effect of bile acid on secretion in the proximal and distal rat colon and coordination of bowel movements in the guinea pig colon.

\section{Methods}

The short-circuit current from the mucosal strip of the proximal and distal rat colon was compared under control conditions after induction of secretion with deoxycholic acid (DCA) as well as after inhibition of secretion with indomethacin, 1,2-bis (o-aminophenoxy) ethane- $N, N, N^{\prime}, N^{\prime}$-tetra-acetic acid (an intracellular calcium chelator; BAPTA), and tetrodotoxin (TTX) using an Ussing chamber. Colonic pressure patterns were also evaluated in the extracted guinea pig colon during resting, DCA stimulation, and inhibition by TTX using a newly developed pressure-sensing artificial stool.

\section{Results}

The secretory response in the distal colon was proportionate to the concentration of DCA. Also, indomethacin, BAPTA, and TTX inhibited chloride secretion in response to DCA significantly $(P<0.05)$. However, these changes were not detected in the proximal colon. When we evaluated motility, we found that DCA induced an increase in luminal pressure at the proximal, middle, and distal sensors of an artificial stool simultaneously during the non-peristaltic period $(P<0.05)$. In contrast, during peristalsis, DCA induced an increase in luminal pressure at the proximal sensor and a decrease in pressure at the middle and distal sensors of the artificial stool $(P<0.05)$.

\section{Conclusions}

DCA induced a clear segmental difference in electrogenic secretion. Also, DCA induced a more powerful peristaltic contraction only during the peristaltic period.

(J Neurogastroenterol Motil 2017;23:606-615)

\section{Key Words}

Colon; Deoxycholic acid; Gastrointestinal motility; Peristalsis; Secretion

Received: November 24, 2016 Revised: February 18, 2017 Accepted: March 12, 2017

(a) This is an Open Access article distributed under the terms of the Creative Commons Attribution Non-Commercial License (http://creativecommons. org/licenses/by-nc/4.0) which permits unrestricted non-commercial use, distribution, and reproduction in any medium, provided the original work is properly cited.

*Correspondence: Jung Ho Park, MD Department of Internal Medicine, Sungkyunkwan University School of Medicine, Kangbuk Samsung Hospital, 29 Saemunan-ro, Jongno-gu, Seoul 03181, Korea

Tel: +82-2-2001-2059, Fax: +82-2-2001-2485, E-mail: pjho3@hotmail.com 


\section{Introduction}

A high concentration of bile acids can induce watery diarrhea in the human large colon. Chronic diarrhea is caused by unabsorbed bile acids in cases of ileal resection up to $100 \mathrm{~cm},{ }^{1}$ and agents that sequester bile acid cause a reduction in diarrhea without interfering with the metabolism of fat or bile acid. ${ }^{2}$ Several mechanisms are involved in the development of diarrhea secondary to unabsorbed bile acids. Bile acids have a direct secretory effect on colonic enterocytes, ${ }^{3}$ and indirectly induce a secretory response by stimulating mast cells or intrinsic neural arcs. ${ }^{4,5}$

In addition, the introduction of bile acids into the human sigmoid colon and rectum stimulates colonic motility, ${ }^{6}$ and chenodeoxycholate significantly accelerates colon transit time in healthy subjects. ${ }^{7}$ A failure to reabsorb bile acid was also suggested to be a cause of diarrhea owing to excess bile acids entering the colon. ${ }^{8}$ Recently, bile acids have been suggested to play an important role in irritable bowel syndrome with diarrhea. Idiopathic adult onset bile acid malabsorption is not rare in irritable bowel syndrome with predominant diarrhea (IBS-D), ${ }^{9}$ and increased bile acid biosynthesis is associated with IBS-D. ${ }^{10,11}$ The role of bile acid in the development of gastrointestinal symptoms has become more important than ever.

However, in previous studies, segmental heterogeneity ${ }^{12}$ has not been considered in bile acid induced secretion experiments, and in terms of colonic motility, peristaltic movement was evaluated only by measuring muscular contractility, not by determining changes in intracolonic pressure along a peristaltic wave. ${ }^{13}$ Therefore, in the present study, we aim to evaluate the existence of segmental heterogeneity of colonic secretion to deoxycholic acid (DCA), and the actual influence of DCA on peristalsis using a newly-developed sensor system. DCA is the most prominent secondary bile acid in human beings. ${ }^{14}$

\section{Materials and Methods}

\section{Animals}

Thirty-six female Sprague-Dawley rats (300-400 g) were used in the secretion study. Rats were euthanized by intravenous injection of sodium pentobarbital $(45 \mathrm{mg} / \mathrm{kg}$ ) and ketamine $(15 \mathrm{mg} / \mathrm{kg})$. All animal protocols were performed in accordance with Animal Experiment Guidelines of Kangbuk Samsung Hospital and approved by the Animal Care Committee. The colon was immediately removed, opened longitudinally, and washed with oxygenated Krebs solution $\left(\mathrm{NaCl} 125 \mathrm{mM}, \mathrm{KCl} 5.9 \mathrm{mM}, \mathrm{CaCl}_{2} 2.5 \mathrm{mM}, \mathrm{MgCl}_{2}\right.$ $1.2 \mathrm{mM}, \mathrm{NaHCO}_{3} 15.5 \mathrm{mM}, \mathrm{NaH}_{2} \mathrm{PO}_{4} 1.2 \mathrm{mM}$, glucose 11.5 $\mathrm{mM} ; \mathrm{pH}$ 7.4). Then, the serosa and muscle were removed under light microscopy to obtain a stripped epithelium. To evaluate the secretory responses of the proximal and distal colon, colonic segments within $2-3 \mathrm{~cm}$ from the ileocecal valve and $4-5 \mathrm{~cm}$ from the anus were used, respectively.

To evaluate peristalsis, guinea pigs were used instead of rats, since most experiments on intestinal peristalsis using artificial pellets and isolated colon were performed with guinea pig colon. Six male guinea pigs $(250-400 \mathrm{~g})$ were used in this experiment. They were sacrificed by $\mathrm{CO}_{2}$ inhalation overdose and exsanguination. Then, the abdominal cavity was opened and an approximately 10 $\mathrm{cm}$ segment of the distal colon was removed. After removal of stools inside the colon, the colonic segment was placed immediately in an organ bath with Krebs solution. In our preliminary study, peristaltic movement could rarely be seen in the proximal colon of guinea pigs. Therefore, the distal colon (where the proximal end of the colonic segment was defined as being $10 \mathrm{~cm}$ away from the anus) was used to evaluate peristalsis.

\section{Secretion in the Proximal and Distal Colonic Mucosa Using an Ussing Chamber}

Stripped epithelium was mounted in a tissue holder with a window size of $2 \mathrm{~mm}$. Because proximal and extracellular solutions were continuously perfused at a rate of $10-20 \mathrm{~mL} / \mathrm{min}$, the effects of various drugs could be evaluated sequentially in the same tissue. The $\mathrm{pH}$ was adjusted to 7.4 and the bath solution was heated with a water jacket. All experiments were performed at a temperature of $37^{\circ} \mathrm{C}$. The time between the removal of the epithelium and the mounting in the Ussing chamber was about 30 minutes, during which time it was maintained in a oxygenated phosphate buffered solution at $4^{\circ} \mathrm{C}$. The experiment was performed under open circuit conditions and the transepithelial voltage $\left(\mathrm{V}_{\mathrm{te}}\right)$ value, which refers to the serum side of the epithelium, was used. The transepithelial resistance $\left(\mathrm{R}_{\mathrm{te}}\right)$ was determined by the application of short (1 second) current pulses (change $[\Delta]$ at $I=0.5 \mu \mathrm{A}$ ). The voltage deviation obtained when no tissue was present in the chamber was subtracted from the voltage deviation obtained when the chamber was present. After an equilibration period of 30 minutes, chloride secretion was evoked by treatment of DCA $0.5 \mathrm{mM}$ on the luminal and basolateral sides. In the next step, to evaluate the secretory mechanism, calcium-dependent chloride secretions were blocked by 1,2-bis(oaminophenoxy)ethane- $N, N, N^{\prime}, N^{\prime}$-tetra-acetic acid (BAPTA), and cAMP and calcium-dependent chloride secretions were blocked 
by indomethacin, while secretion was stimulated by DCA. Lastly, secretion was measured after the addition of tetrodotoxin (TTX).

\section{Quantitative real-time polymerase chain reaction for $\mathrm{G}$ protein-coupled bile acid receptor 1}

$\mathrm{G}$ protein-coupled bile acid receptor 1 (GpBAR1) is the bile acid receptor that is expressed in rat colonic epithelium, enterochromaffin cells, and myenteric neurons in the colon. ${ }^{14,16}$ The polymerase chain reaction (PCR) amplification was performed in a LightCycler 480 Real-Time PCR System (Roche Applied Science, Indianapolis, IN, USA) in 96 well plates. PCR mix contained $2 \mu \mathrm{L}$ cDNA template, $2 \mu \mathrm{L}$ of primer mix and $10 \mu \mathrm{L}$ of LC480 SYBR Green I Master Mix from the LC480 SYBR Green I Master kit (Roche). Plate layout design was maintained for triplicates of the samples according to rat GpBAR1 (forward 5'-cactgcccttctctctgtcc-3'; reverse 5'-agttcaggtccagttacgc-3') and rat glyceraldehyde-3-phosphate dehydrogenase (GAPDH) (forward 5'-ggtgctgagtatgtcgtgga-3'; reverse 5'-gtggttcacacccatcacaa-3'), 3 wells for negative. The PCR protocol included 1 cycle of polymerase activation for 10 minutes at $95^{\circ} \mathrm{C}, 45$ cycles of amplification with 10 seconds denaturation at $95^{\circ} \mathrm{C}, 1$ minute annealing at $55^{\circ} \mathrm{C}$, and 5 seconds extension at $72^{\circ} \mathrm{C}$ in each cycle and 1 cycle for melting curve analysis with 10 seconds denaturation at $95^{\circ} \mathrm{C}, 1$ minute annealing at $60^{\circ} \mathrm{C}$ and a melting step at $98^{\circ} \mathrm{C}$ at $0.2^{\circ} \mathrm{C} / \mathrm{sec}$ ramp rate. Each sample was run in triplicate.

\section{Peristaltic Evaluation of Guinea Pig Large Intestine Using an Artificial Stool with Serial Capacitive Sensors}

\section{Development of a pressure-sensing artificial stool}

To mimic real guinea pig excrement, we designed an artificial pellet $(4 \times 9 \mathrm{~mm}$ in size and the surface area of the proximal and distal segments was $4.7 \mathrm{~mm}^{2}$, while that of the middle segment was $5.05 \mathrm{~mm}^{2}$ ) and attached it to the packaged sensor. The artificial pellet was made of polylactic acid and formed by 3-dimensional printing (Fig. 1A). The proposed pressure sensor was designed with careful consideration of the structure and motility mechanism of the guinea pig large intestine. Three pressure sensors were mounted, one each on the proximal, middle, and distal portions of the artificial pellet, in order to provide some redundancy in the size and shape of the artificial guinea pig feces. The capacitance of a prototype sensor was recorded as 2.5-3.0 pF. This capacitance value was later converted to a count value using a lab-fabricated data conversion system. The sensitivity of the pressure sensor was recorded as below
A (a) Polyamide film cleaning

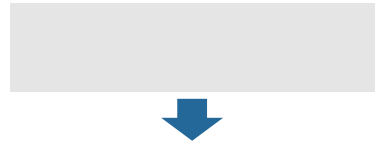

(b) Titanium/Copper seed layer

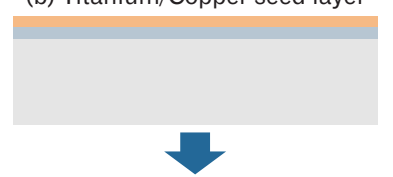

(c) Photoresister coating

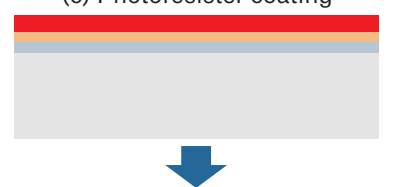

(d) Ultraviolet exposure
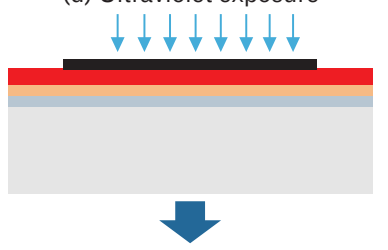

(e) Photolithography

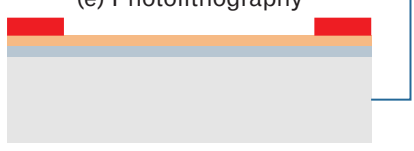

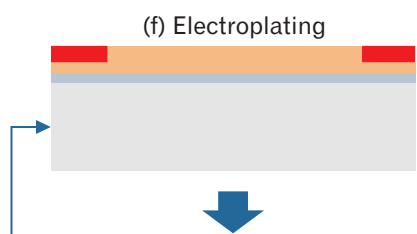

(g) Photoresister remove

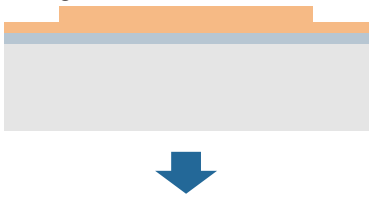

(h) Seed layer etching

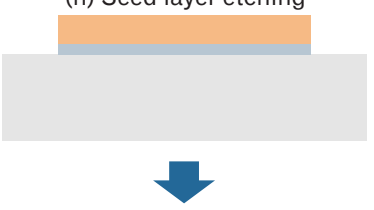

(i) Adhesive bonding

\section{B}

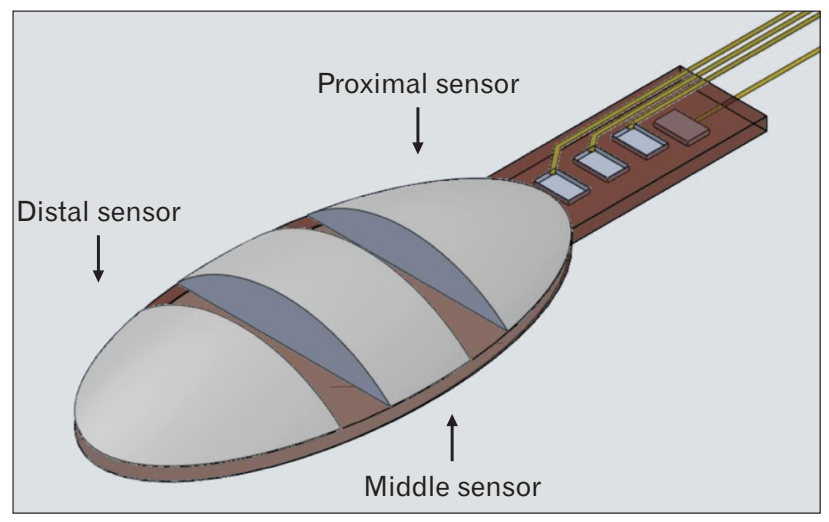

Figure 1. Fabrication sequence for the sensor and schematic of pressure-sensing artificial stool. (A) [a] Polyamide was chosen for the substrate with consideration of microfabrication and biocompatibility. [b] The surface was covered by titanium/copper (Ti/Cu, 20/300 nm) films by sputtering for seed layer in the electroplating process. The electrode for capacitor sensors was then shaped by photolithography and formed by $\mathrm{Cu}$ electroplating as shown in [c] and [e]. Then, the unnecessary photoresister and seed layer was removed by a solvent and a metal etchant ([f] to $[\mathrm{h}]$ ). Those electrode formation processes were done on the bottom and upper substrates. [i] To achieve hermeticity of the pressure sensors, the bottom and upper substrates were directly bonded by the assistance of an adhesive film (OCA film; Shin-Chang, Dongducheon, Korea). (B) Location of proximal, middle, and distal sensors on the ovoid shaped artificial stool. 
$1 \mathrm{mmHg}$ per atmospheric pressure (Fig. 1B). Finally, tests for the reproducibility and accuracy of measurements were done using an evaluation system (High precision pressure regulator CPC3000; Mensor San Marcos, Texas, USA), vacuum chamber, network analyzer (HP, 8753E; Palo Alto, CA, USA), and switch module (PXIe-1082; National Instruments; Austin, Texas, USA).

\section{In vitro experiments using pressure-sensing artificial stool}

After an equilibration period of 30 minutes in an organ bath, artificial stool was inserted into the oral side of the colonic segment (10 $\mathrm{cm}$ in length), and then 1,10 , and $100 \mu \mathrm{M}$ DCA were added to the tissue bath. Changes in intraluminal pressure and frequency of colonic contraction were analyzed for 10-15 minutes after the introduction of the drugs. Frequency was calculated using a Fourier series (MATLAB program; MathWorks, Natick, MA, USA) and is expressed in Hertz. In addition, $100 \mu \mathrm{M}$ DCA and $1 \mu \mathrm{M}$ TTX were applied to the tissue bath and motor responses were recorded. The distal colon was used for the study of peristalsis since peristalsis rarely occurs in the proximal colon. All measured values are expressed as the change in pressure from baseline (pressure at rest).

\section{Statistical Methods}

All data are expressed as means \pm standard deviations. Twotailed Student's $t$ tests and ANOVA tests were utilized for the comparison of statistical differences. A $P$-value of $<0.05$ was considered to be significant.

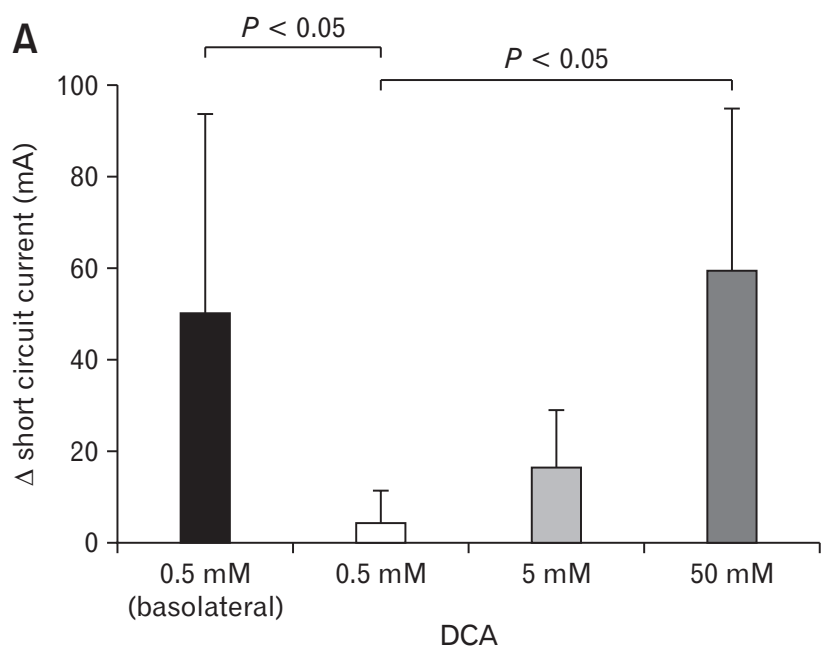

\section{Results}

\section{Secretory Responses of the Proximal and Distal Colon to Bile Acids}

\section{Electrical properties following luminal and basolateral addition of deoxycholic acid}

In the distal colon, the luminal addition of DCA induced an increase in short-circuit current $\left(I_{s c}\right)$ values in a concentrationdependent manner. However, the increase in delta $I_{\mathrm{sc}}$ after the addition of DCA $0.5 \mathrm{mM}$ on the basolateral side was more significant as compared to the secretory responses on the luminal side $\left(\Delta I_{s c}=\right.$ $49.76 \pm 43.83$ and $4.62 \pm 6.83 \mu \mathrm{A} \cdot \mathrm{cm}^{-2}$ for the proximal and distal colon, respectively; $P<0.001, \mathrm{n}=8$ ) (Fig. 2A). When DCA was added to the luminal and basolateral sides of the proximal colon, no significant changes in $I_{s c}$ were seen $(\mathrm{n}=8)$ (Fig. 2B).

\section{Segimental differences of secretory responses following basolateral addition of deoxycholic acid}

When we compared secretory responses between segments, significant differences were detected in $I_{s c}$ after the basolateral addition of $0.5 \mathrm{mM}$ DCA between the values measured in the proximal and distal colon $\left(\Delta I_{s c}=49.76 \pm 43.83\right.$ and $11.45 \pm 15.38 \mu \mathrm{A} \cdot \mathrm{cm}^{-2}$ for the proximal and distal colon, respectively; $P<0.05, \mathrm{n}=8)$.

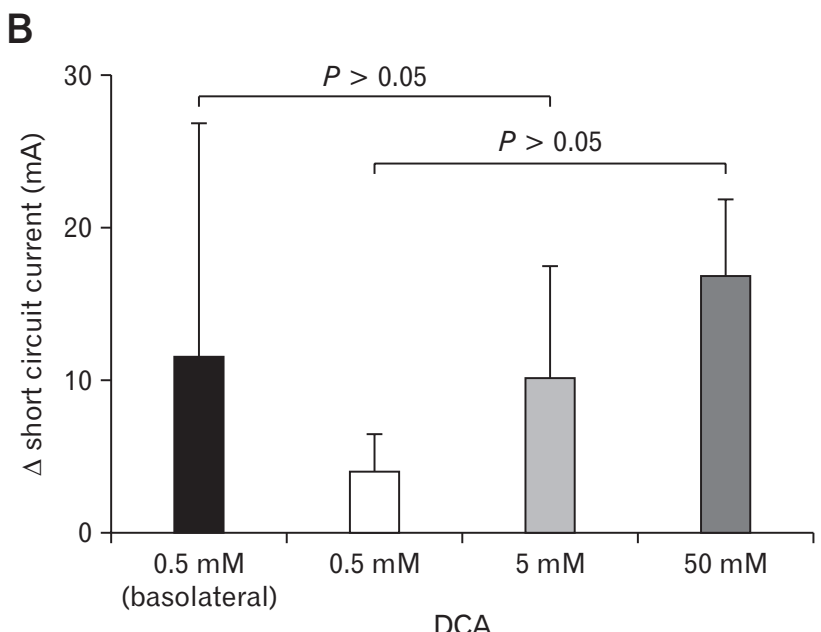

Figure 2. Secretory response to the luminal and basolateral addition of deoxycholic acid (DCA). (A) In the distal colon, the luminal addition of DCA induced an increase in short-circuit current $\left(I_{s c}\right)$ values in a concentration dependent manner $(\mathrm{n}=8)$, and the increase in secretion after the basolateral addition of DCA $0.5 \mathrm{mM}$ was more significant than the secretory responses on the luminal side. (B) When DCA was added to the luminal and basolateral side in the proximal colon, only slight increase of $I_{s c}$ was noted $(\mathrm{n}=8)$. 

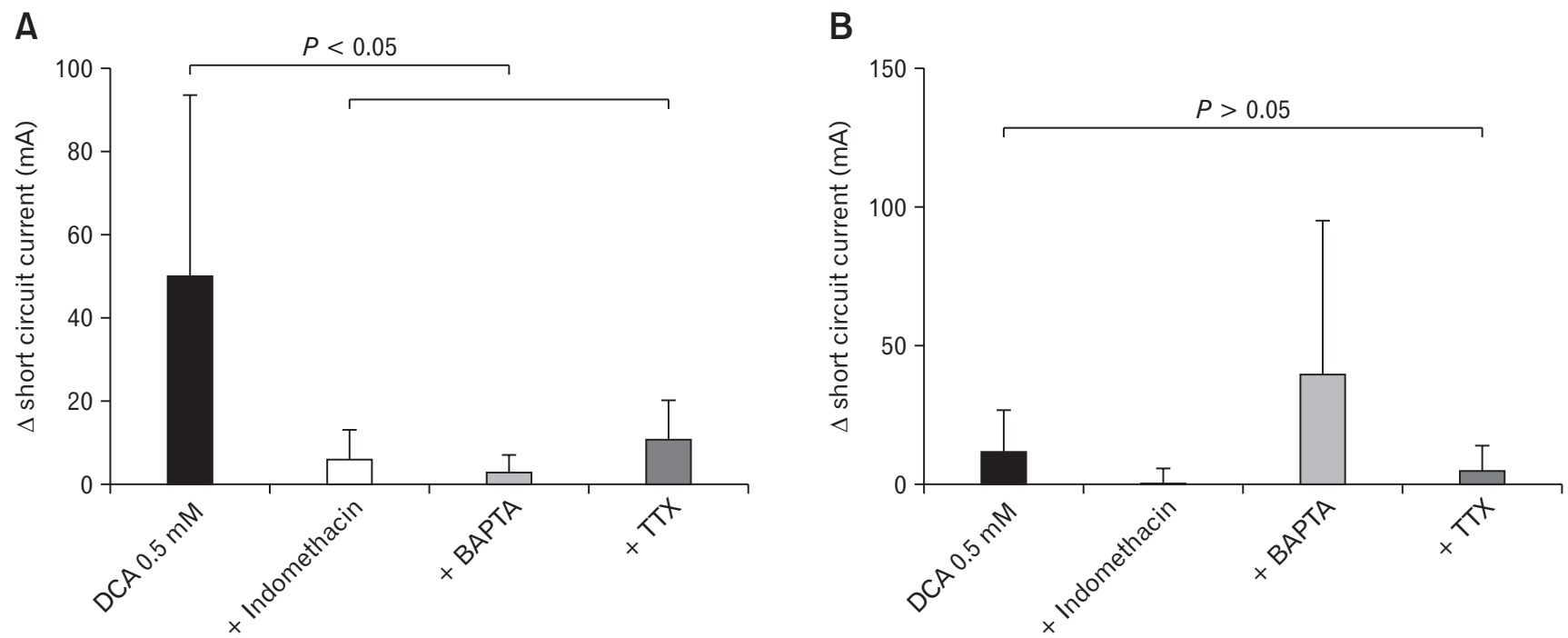

Figure 3. Effect of pretreatment with indomethacin, 1,2-bis(o-aminophenoxy) ethane- $N, N, N^{\prime}, N^{\prime}$-tetra-acetic acid (BAPTA) and tetrodotoxin (TTX) on secretory response of the proximal and distal colon. (A) The basolateral addition of indomethacin, BAPTA and TTX resulted in the abolition of responses to deoxycholic acid (DCA) in the distal colon $(\mathrm{n}=6)$, (B) but not in the proximal colon.

\section{Effects of indomethacin, BAPTA, and tetrodotoxin after addition of deoxycholic acid in the proximal and distal colon}

In the distal colon, the basolateral addition of indomethacin, BAPTA, and TTX resulted in an abolition of responses to DCA. This decrease in delta $I_{s c}$ values was found to be significant $(P<$ 0.05 for the application of indomethacin, BAPTA, and TTX, $\mathrm{n}=$ 6) (Fig. 3A). However, in the proximal colon, pretreatment with indomethacin, BAPTA, and TTX did not have an effect on the secretory responses to DCA ( $P>0.05)$ (Fig. 3B).

\section{Quantitative real-time polymerase chain reaction analysis of $\mathrm{G}$ protein-coupled bile acid receptor 1}

The levels of GpBAR1 expression in the proximal and distal colon were determined using qRT-PCR, with the values normalized to the corresponding GAPDH gene transcription values. The distribution of GpBAR1 was similar in both colonic segments (Fig. 4).

\section{Motor Effects of Bile Acid on the Distal Colon}

\section{Changes in contractility and frequency: during peristal-} tic and non-peristaltic period

During the non-peristaltic period, the addition of $1 \mu \mathrm{mol}$ DCA into the colonic lumen induced a significant increase in pressure at the proximal, middle, and distal sensors of the artificial stool, and the pressure change at the distal sensor was greater than that at

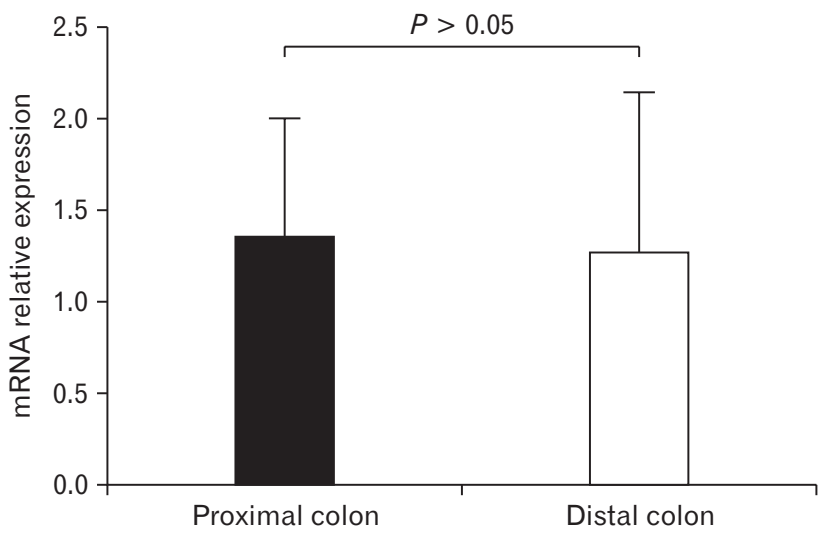

Figure 4. Expression levels of $\mathrm{G}$ protein-coupled bile acid receptor 1 (GpBAR1) between proximal and distal colon. The distribution of GpBAR1 was similar in both colon segments $(n=5)$.

the proximal or middle sensors $(\mathrm{n}=5, P<0.01)$ (Fig. 5A). The increase in pressure at all sensors on an artificial stool was concentration-dependent (Fig. 5B). However, DCA had no effect on the frequency of contraction at the proximal, middle, and distal sensors (Fig. 5C).

However, during the peristaltic period, $1 \mu \mathrm{mol}$ DCA caused a significant increase in pressure only at the proximal sensor of an artificial stool (Fig. 6A), while a notable decrease in pressure at the middle and distal sensors was detected $(\mathrm{n}=4, P<0.05)$ (Fig. 6B and $6 \mathrm{C})$. There was no change in the frequency of contraction at any of the sensors on the artificial stool $(n=4, P>0.05)$. 

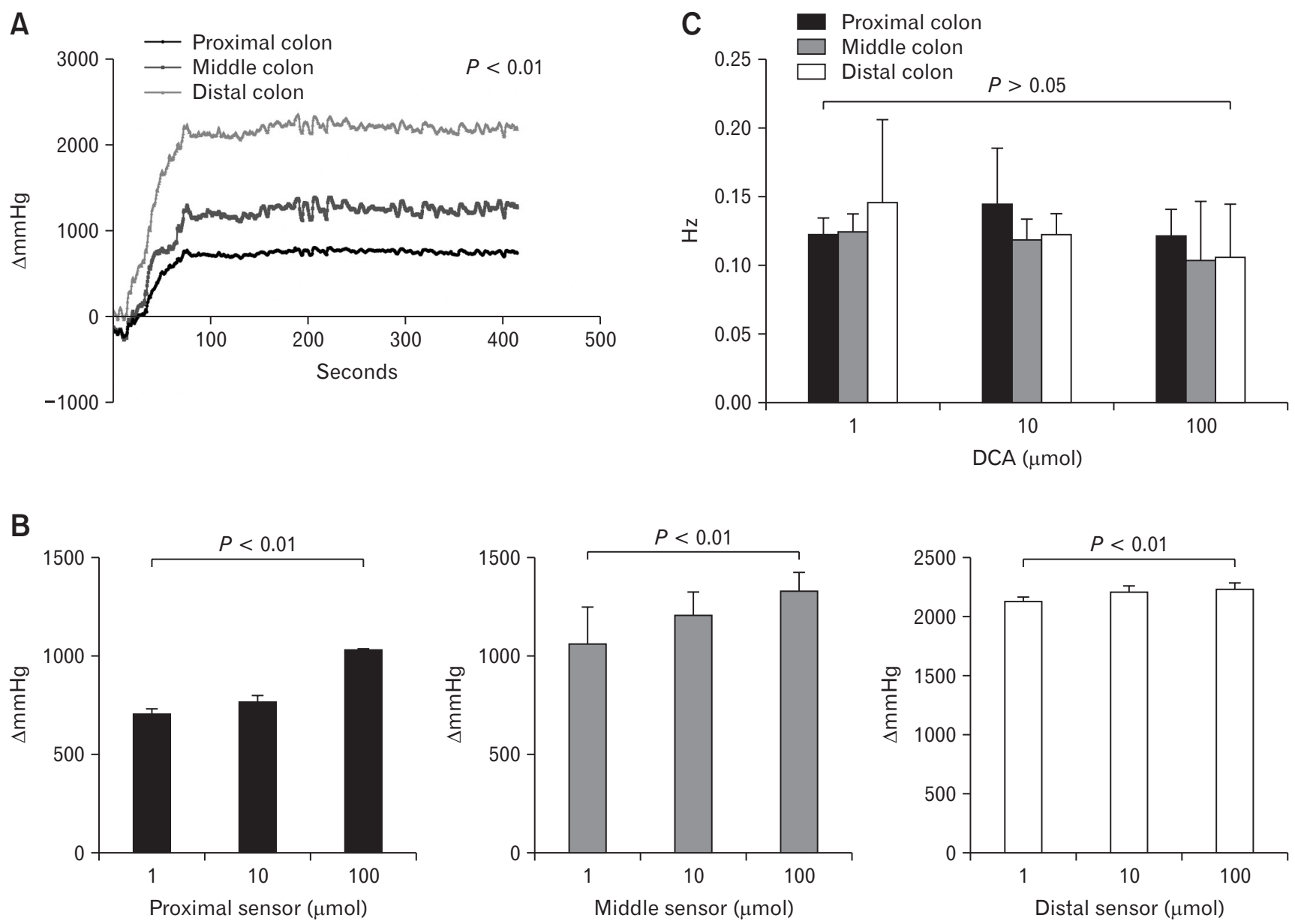

Figure 5. Pressure changes after the addition of deoxycholic acid (DCA) during non-peristaltic period. (A) The addition of DCA $1 \mu$ mol into the colonic lumen induced a significant increase in pressure at all sensors of an artificial stool, and pressure change at the distal sensor was greater than those in the proximal and middle sensors $(n=5)$. (B) Increase in pressure at all sensors was concentration dependent. (C) DCA had no effect on the frequency of contraction at the proximal, middle, and distal sensors of an artificial stool.

\section{Change in contractility with the addition of tetrodotoxin during $100 \mu \mathrm{mol}$ deoxycholic acid-induced contraction}

At first, pretreatment with TTX significantly increased pressure at the proximal and distal sensors of an artificial stool $(n=5$, $P<0.01$ ) (Fig. 7). However, this change gradually disappeared over time.

\section{Discussion}

In this study, we showed that DCA induced a significant secretory response in the distal colon, and secretion was inhibited by indomethacin, BAPTA, and TTX. However, in the proximal colon, DCA caused only a slight secretory response and secretion was not inhibited by indomethacin, BAPTA, or TTX. Furthermore, during the non-peristaltic period, application of DCA induced a concentration-dependent increase in pressure at the proximal, middle and distal parts of an artificial stool. However, when DCA was added during peristalsis, pressure at the proximal part was significantly increased while pressure at the distal and middle parts was notably decreased compared with control pressure. Addition of TTX did not inhibit colonic contractility at first, but colonic contractility tended to decrease slowly as time passed.

We also observed that the secretory response induced by basolateral addition of DCA was 10 to 100 times more prominent than that caused by luminal addition of DCA in the distal colon; this result is consistent with that of previous reports. ${ }^{17}$ Actually, efficient ileal conservation, together with rapid bacterial modification of bile acids entering the colon, results in the aqueous concentration of 
A
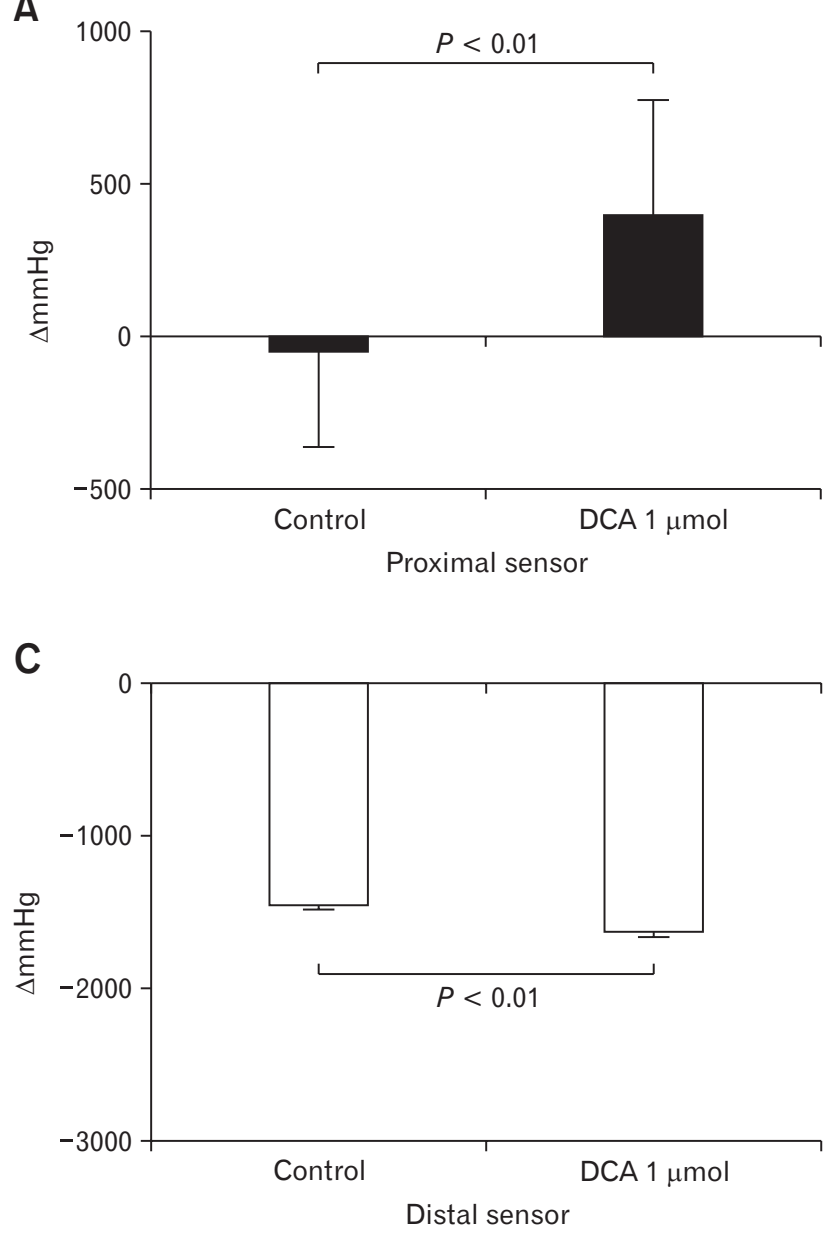

A

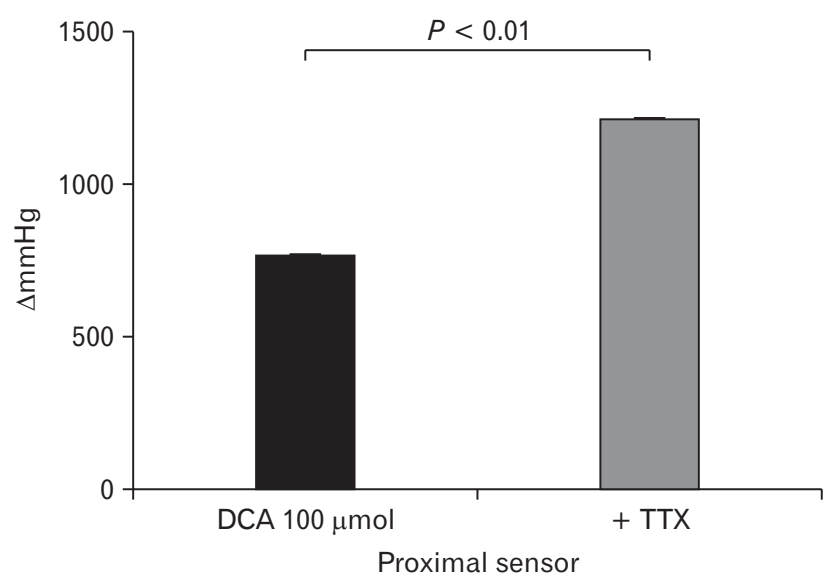

B

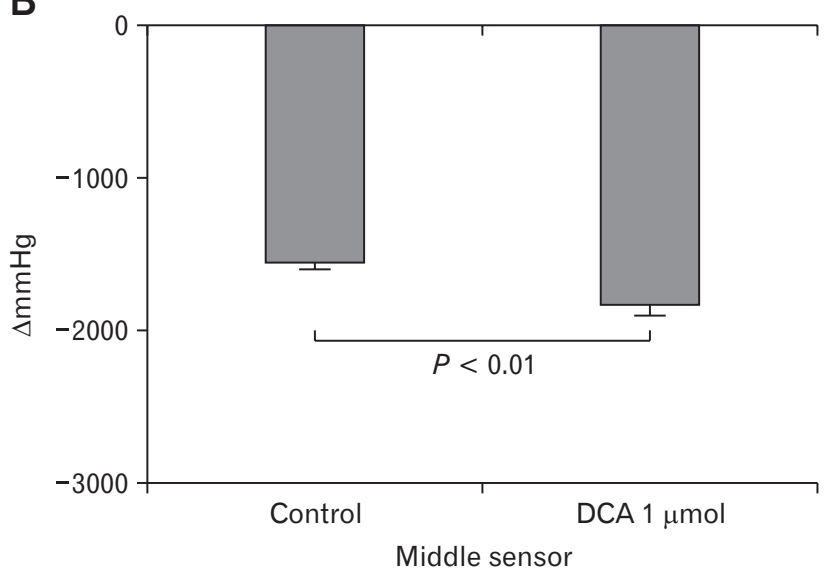

Figure 6. Pressure changes after the addition of deoxycholic acid (DCA) during the peristaltic period. (A) DCA $1 \mu \mathrm{mol}$ caused a significant increase in pressure at the proximal sensor of an artificial stool, and (B and C) a notable decrease of pressure at the middle and distal sensors $(n=4)$.

B

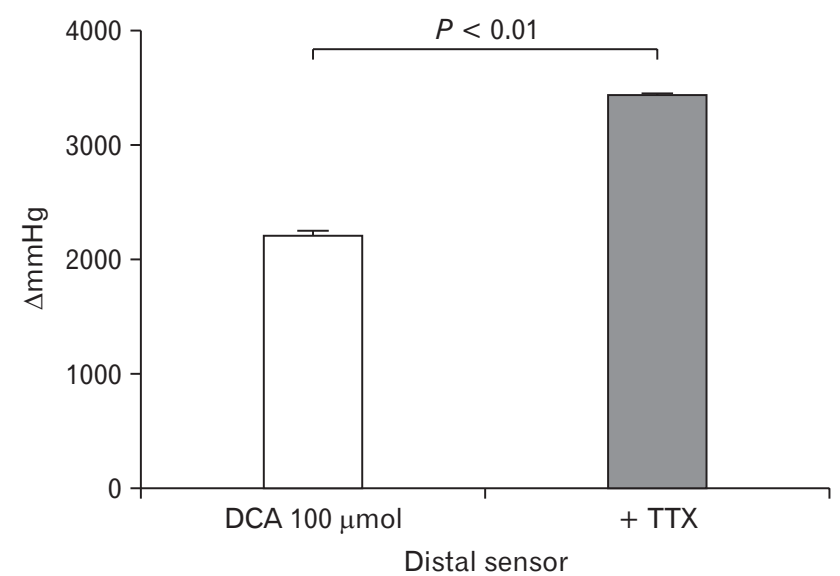

Figure 7. Pressure changes on the distal sensors (deoxycholic acid [DCA] $100 \mu \mathrm{mol}+$ tetrodotoxin [TTX]). At first, pretreatment of TTX significantly increased pressure at the proximal (A) and distal sensors (B) of an artificial stool. However, this change gradually disappeared over time ( $\mathrm{n}=5$ ). 
bile acids in the colon being quite low, $<1 \mathrm{mM} .^{18}$ The circulating DCA pool is only about $0.66 \mathrm{~g}(1.7 \mathrm{mM}) .{ }^{19}$ Therefore, the physiologic concentration of luminal DCA might not have an effect on the secretory response at all. Alternatively, if DCA could enter the basolateral side of the colonic epithelium, perhaps because of inflammation or mucosal breakage, the possibility of inducing a secretory response would be much higher. ${ }^{17}$

Application of DCA induced a marked increase in $I_{s c}$ in the proximal and distal colon, and the increase in $I_{s c}$ in the distal colon was greater than that in the proximal colon. This segmental heterogeneity in the secretory responses is consistent with the results of previous reports. The distal segments of the rat colon were more sensitive to both carbachol and forskolin than were the proximal segments ${ }^{20}$ and similar results were reported in the human ascending colon and rectum. ${ }^{12}$ In terms of secretory mechanisms, our results are in line with those of previous studies; stimulation of a colonic mucosal cAMP system is strongly implicated in mediating DCA-induced colonic secretion, ${ }^{21}$ and DCA probably activates $\mathrm{Ca}^{2+}$-regulated $\mathrm{K}^{+}$conductance and acts on non-epithelial cells to activate $\mathrm{Cl}^{-}$secretion indirectly ${ }^{17}$ However, some of our results appear to contradict those of previous reports. Activation of GpBAR1 rapidly decreased basal chloride secretion and attenuated the chloride-mediated secretory response to a cholinergic agent. ${ }^{16}$ This discrepancy may be due to differences in agonist action on GpBAR1. Ursodeoxycholic acid and lithocholic acid attenuate colonic epithelial secretory function ${ }^{22,23}$ In contrast, DCA activates ion channels in colonocytes and acts on non-epithelial cells to activate chloride secretion indirectly. ${ }^{17}$ Furthermore, pretreatment with TTX changed the secretory responses to DCA, confirming that the nervous system is associated with secretion induced by DCA. Considering that the effects of GpBAR1 activation are independent of the ENS, ${ }^{16}$ DCA may induce secretory responses in the colon by a dual mechanism consisting of GpBAR1 activation and neuronal activity. In the proximal colon, addition of basolateral DCA only induced a slight increase in $I_{\mathrm{sc}}$ and pretreatment with indomethacin, BAPTA, or TTX did not change the electrical properties. This indicates that the proximal colon is not responsible for the secretory response to DCA. A similar result was found in the human proximal colon. ${ }^{12}$ However, there is also a possibility that the lack of secretory response to DCA in the proximal colon might lead to low sensitivity of proximal colon to the BAPTA and TTX.

DCA had a different effect on colonic contractility according to whether peristalsis did or did not occur. During the non-peristaltic period, DCA induced a significant increase in pressure at the proximal, middle, and distal parts of an artificial stool simultaneously.
This pattern of increased contractility did not accelerate propulsion of the artificial stool. However, during the peristaltic period, DCA caused faster movement of an artificial stool by increasing pushing strength and decreasing resistance at the distal part of the artificial stool. This result was not dependent upon the way DCA was administered (intraluminally or extraluminally). These results are partly consistent with a previous report that mucosal application of DCA stimulated ascending contraction and descending relaxation of the colonic circular muscle, thus inducing peristalsis. ${ }^{14}$ Bile acids are known to activate GpBAR1, which is expressed by enterochromaffin cells and intrinsic primary afferent neurons, and the release of 5-hydroxytryptamine and calcitonin gene-related peptide, the major transmitters of the afferent limb of the peristaltic reflex. ${ }^{13}$

In terms of the efficacy of DCA on the peristaltic reflex, DCA was suggested to stimulate migrating action potential complexes (MAPC) in the colon, and the increase in MAPC activity is dependent on intact cholinergic and alpha adrenergic neurons. ${ }^{24} \mathrm{Also}$, full-thickness segments of mouse colon stimulated by various GpBAR1 agonists induced peristalsis in mice. ${ }^{14}$ However, an increase in the peristaltic reflex in previous reports was estimated by wholegut transit time and defecation frequency, not by the actual number of peristaltic movements. Shortened whole-gut transit time does not necessarily indicate an increased frequency of the peristaltic reflex. In the present study, DCA did not increase the frequency of peristaltic movements, and instead only strengthened the propulsive power on the artificial stool. Considering these results, the decreased transit times seen in a previous study might be caused by faster movement of an artificial stool instead of by increased frequency of the peristaltic reflex.

Luminal bile acids exert region-specific actions in the intestine. They inhibit motility of the small intestine, ${ }^{25}$ while stimulating motility in the large intestine. ${ }^{26}$ Segmental heterogeneity also exists inside the large intestine. The peristaltic reflex could be easily induced only in the distal colon of the guinea pig, but not in the proximal colon. This heterogeneity may be caused by differences in neuronal innervation rather than by differences in the distribution of $\mathrm{Gp}$ BAR1, because the distribution of GpBAR1 was similar in both colonic segments. Furthermore, rat colon was not suitable for the evaluation of peristalsis, since artificial stools rarely induce the peristaltic reflex in the rat colon. For that reason, guinea pig colon was used in the present study. Thus, species diversity was also shown through our experiments.

One interesting finding of this study is that DCA induced increased contractility after pretreatment with TTX. This result was contrary to our expectations. Possible explanations are as follows. 
First, rhythmic phasic contractions of the human sigmoid colon are not affected by TTX. This lack of effect of TTX demonstrated the non-neuronal origin of rhythmic phasic contractions ${ }^{27}$ and an unbalanced effect of TTX on excitatory and inhibitory enteric motor neurons could increase colonic contractility for a short time. Actually, first-stage gastrointestinal symptoms after TTX intoxication include nausea, vomiting, diarrhea, and abdominal pain, rather than paralytic ileus. Secondly, the experiment was not long enough to identify a relaxation response after pretreatment with TTX. Owing to the viability of a resected colon, 2 hours was the maximum experimental time.

In conclusion, DCA induced a clear segmental difference in electrogenic secretion. Also, DCA caused a general increase in the pressure of spontaneous colonic contractions during the nonperistaltic period. However, during the peristaltic period, DCA induced a more powerful peristaltic movement in the distal colon.

\section{Financial support: None.}

\section{Conflicts of interest: None.}

Author contributions: Nam Hee Kim: wrote the manuscript; Jung Ho Park: planned the study; and Jae-soon Park and YeunHo Joung: made sensors.

\section{References}

1. Aldini R, Roda A, Festi D, et al. Bile acid malabsorption and bile acid diarrhea in intestinal resection. Dig Dis Sci 1982;27:495-502.

2. Jacobsen O, Højgaard L, Hylander Møller E, et al. Effect of enterocoated cholestyramine on bowel habit after ileal resection: a double blind crossover study. Br Med Jr (Clin Res Ed) 1985;290:1315-1318.

3. Huang X, Heyman M, Nath S, Castagna M, Desjeux J. Distinct signaling mediates chloride secretion induced by tumor promoter bile-salts and phorbol esters in human colonic cells. Int J Oncol 1995;6:1159-1163.

4. Gelbmann CM, Schteingart CD, Thompson SM, Hofmann AF, Barrett KE. Mast cells and histamine contribute to bile acid-stimulated secretion in the mouse colon. J Clin Invest 1995;95:2831-2839.

5. Sun Y, Fihn BM, Sjövall H, Jodal M. Enteric neurones modulate the colonic permeability response to luminal bile acids in rat colon in vivo. Gut 2004;53:362-367.

6. Kirwan WO, Smith AN, Mitchell WD, Falconer JD, Eastwood MA. Bile acids and colonic motility in the rabbit and the human. Gut 1975;16:894-902.

7. Odunsi-Shiyanbade ST, Camilleri M, McKinzie S, et al. Effects of chenodeoxycholate and a bile acid sequestrant, colesevelam, on intestinal transit and bowel function. Clin Gastroenterol Hepatol 2010;8:159-165.
8. Walters JR, Tasleem AM, Omer OS, Brydon WG, Dew T, le Roux CW. A new mechanism for bile acid diarrhea: defective feedback inhibition of bile acid biosynthesis. Clin Gastroenterol Hepatol 2009;7:11891194.

9. Wedlake L, A'Hern R, Russell D, Thomas K, Walters JR, Andreyev HJ. Systematic review: the prevalence of idiopathic bile acid malabsorption as diagnosed by SeHCAT scanning in patients with diarrhoea-predominant irritable bowel syndrome. Aliment Pharmacol Ther 2009;30:707-717.

10. Wong BS, Camilleri M, Carlson P, et al. Increased bile acid biosynthesis is associated with irritable bowel syndrome with diarrhea. Clin Gastroenterol Hepatol 2012;10:1009-1015, e3.

11. Bajor A, Gillberg PG, Abrahamsson H. Bile acids: short and long term effects in the intestine. Scan J Gastroenterol 2010;45:645-664.

12. Park JH, Rhee PL, Lee JH, et al. Segmental heterogeneity of electrogenic secretions in human ascending colon and rectum. Int J Colorectal Dis 2006;21:357-364.

13. Alemi F, Poole DP, Chiu J, et al. The receptor TGR5 mediates the prokinetic actions of intestinal bile acids and is required for normal defecation in mice. Gastroenterology 2013;144:145-154.

14. Keating N, Mroz MS, Scharl MM, et al. Physiological concentrations of bile acids down-regulate agonist induced secretion in colonic epithelial cells. J Cell Mol Med 2009;13:2293-2303.

15. Barcelo A, Claustre J, Toumi F, et al. Effect of bile salts on colonic mucus secretion in isolated vascularly perfused rat colon. Dig Dis Sci 2001;46:1223-1231.

16. Ward JB, Mroz MS, Keely SJ. The bile acid receptor, TGR5, regulates basal and cholinergic-induced secretory responses in rat colon. Neurogastroenterol Motil 2013;25:708-711.

17. Mauricio AC, Slawik M, Heitzmann D, et al. Deoxycholic acid (DOC) affects the transport properties of distal colon. Pflugers Arch 2000;439:532-540.

18. Hofmann AF. Bile acids: the good, the bad, and the ugly. News Physiol Sci 1999;14:24-29.

19. Marcus SN, Heaton KW. Intestinal transit, deoxycholic acid and the cholesterol saturation of bile - three inter-related factors. Gut 1986;27:550558.

20. Nobles M, Diener M, Mestres P, Rummel W. Segmental heterogeneity of the rat colon in the response to activators of secretion on the cAMP-, the cGMP- and the $\mathrm{Ca}^{2+}$-pathway. Acta Physiol Scand. 1991;142:375386.

21. Conley DR, Coyne MJ, Bonorris GG, Chung A, Schoenfield LJ. Bile acid stimulation of colonic adenylate cyclase and secretion in the rabbit. AM J Dig Dis 1976;21:453-458.

22. Kelly OB, Mroz MS, Ward JB, et al. Ursodeoxycholic acid attenuates colonic epithelial secretory function. J Physiol 2013;591:2307-2318.

23. Ao M, Domingue JC, Khan N, et al. Lithocholic acid attenuates cAMPdependent $\mathrm{Cl}$ - secretion in human colonic epithelial T84 cells. Am J Physiol Cell Physiol 2016;310:C1010-C1023.

24. Shiff SJ, Soloway RD, Snape WJ Jr. Mechanism of deoxycholic acid stimulation of the rabbit colon. J Clin Invest 1982;69:985-992.

25. Penagini R, Misiewicz JJ, Frost PG. Effect of jejunal infusion of bile acids on small bowel transit and fasting jejunal motility in man. Gut 
1988;29:789-794.

26. Snape WJ Jr, Shiff S, Cohen S. Effect of deoxycholic acid on colonic motility in the rabbit. Am J Physiol 1980;238:G321-G325.
27. Aulí M, Martínez E, Gallego D, et al. Effects of excitatory and inhibitory neurotransmission on motor patterns of human sigmoid colon in vitro. $\mathrm{Br}$ J Pharmacol 2008;155:1043-1055. 